Available online on 15.02.2019 at http://jddtonline.info
(c) 2011-18, publisher and licensee JDDT, This is an Open Access article which permits unrestricted
non-commercial use, provided the original work is properly cited

Open $\overbrace{\text { Access }}$

Research Article

\title{
Molecular docking of fisetin as a multi-target drug in the treatment of Parkinson's disease
}

\author{
Malathi Rajendran ${ }^{1,2 *}$, Dr. K Prashanthi ${ }^{2}$ and Dr. J. Karthikeyan ${ }^{3}$ \\ ${ }^{1}$ Department of Biochemistry, Research and Development Centre, Bharathiar University, Coimbatore - 641046, Tamil Nadu, India, \\ ${ }^{2}$ Department of Biochemistry, Indian Academy Degree College Autonomous, Bengaluru - 560043, Karnataka, India, \\ ${ }^{3}$ Department of Biochemistry, Kongunadu Arts and Science College Autonomous, Coimbatore, Tamil Nadu, India
}

\begin{abstract}
Fisetin is found in various fruits and vegetables. It is reported to have neurotropic, anti-inflammatory, anti-carcinogenic and also other health benefits. Fisetin has been proved to have neuroprotective effect against Parkinson's disease (PD). Elucidation of the molecular interaction of fisetin with various anti-parkinsonian drug targets leads to better understanding mode of action of the drug. The present study is aimed to study the molecular interaction of fisetin with molecular targets having potential role in PD. The molecular properties and drug likeness model score were first analysed for flavonoid fisetin, which was found to be 0.76 . The structures of the molecular drug targets, such as MAO A (2BXR), MAO B (2BYB), COMT (2AVD) and tyrosine hydroxylase (2XSN), was extracted from RCSB-Protein Data Bank. Molecular docking was performed using AUTO DOCK-4.2. The docking scores were evaluated by analyzing the minimum binding energy for the first five runs for all the target proteins. The minimum binding energy for MAO A (2BXR), MAO B (2BYB), COMT (2AVD), tyrosine hydroxylase (2XSN) were -10.22 kcal/mol, -9.68 $\mathrm{kcal} / \mathrm{mol},-7.45 \mathrm{kcal} / \mathrm{mol}$ and $-6.67 \mathrm{kcal} / \mathrm{mol}$ respectively. Out of the 4 potential PD drug targets, MAO A and MAO, genes responsible for oxidative deamination of dopamine, are predicted to have the least minimum binding energy and best interaction with fisetin.
\end{abstract}

Keywords: Fisetin, docking, multidrug targets, autodock, MAO A, MAO B, COMT, Tyrosine hydroxylase

Article Info: Received 04 Dec 2018; $\quad$ Review Completed 16 Jan 2019; $\quad$ Accepted 17 Jan 2019; Available online 15 Feb 2019

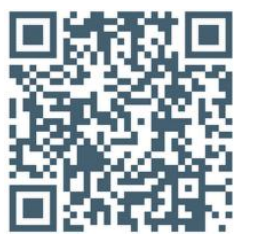

\section{Cite this article as:}

Malathi Rajendran, Prashanthi K, Karthikeyan J, Molecular docking of fisetin as a multi-target drug in the treatment of Parkinson's disease, Journal of Drug Delivery and Therapeutics. 2019; 9(1-s):1-4 http://dx.doi.org/10.22270/jddt.v9i1-s.2232

Malathi Rajendran, Department of Biochemistry, Research and Development Centre, Bharathiar University, Coimbatore - 641046, Tamil Nadu, India. Email: malathianand26@gmail.com

\section{INTRODUCTION}

Parkinson's disease is characterized by progressive loss of dopaminergic neurons in the substantia nigra, leading to the loss of motor skills ${ }^{1-4}$. The key causative factors that might influence disease outcomes include buildup of reactive oxygen species (ROS), selective loss of neurons, loss of mitochondrial membrane potential and ATP depletion 5. Flavonoid, fisetin has gained great interest due to its diverse pharmacological effects, such as antioxidant, antiinflammatory, anticancer and antihypertensive action, among others ${ }^{6}$. The impaired function of Parkinson disease can be ameliorated by using flavonoid fisetin, which has high antioxidative and neuroprotective activities ${ }^{7}$.

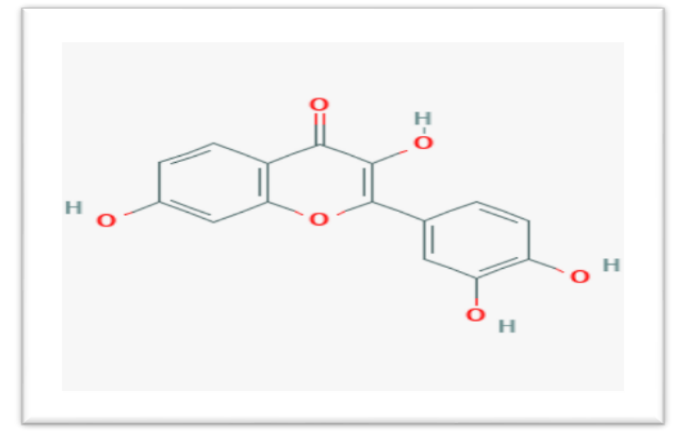

Figure 1: Molecular structure of fisetin. https://pubchem.ncbi.nlm.nih.gov/image/imagefly.cgi?cid=5 $\underline{281614 \& \text { width }=300 \text { \& height }=300}$ 
The emerging neuroprotective therapies are not effective due to restricted understanding of the important molecular event that stimulate neurodegeneration. The causes PD pathogenesis is thought to be due to the misfolding of proteins, dysfunction mitochondria \& the ubiquitin proteasome pathway, oxidative stress and deregulation dopamine metabolism ${ }^{8}$. The major enzymes involved in dopamine metabolism include MAO A, MAO B, COMT - involved in dopamine degradation and tyrosine hydroxylase - involved in dopamine synthesis. The main objective of this study was to dock the flavonoid fisetin as ligand with the molecular targets of Parkinson's disease. In silico methods are regularly used in modern drug design to help apprehend drug-target protein interactions. The results obtained from this study would be useful in understanding the mechanism of neuro-protective effect of fisetin.

\section{MATERIALS AND METHODS}

\section{Preparation of the protein and Ligand Structures}

The three dimensional X-ray structure of MAO A (2BXR), MAO B (2BYB), COMT (2AVD), tyrosine hydroxylase (2XSN) was obtained from RCSB Protein Data Bank. The structure was refined by removing water molecules and other complexed molecules. Hydrogen atoms were added and electronic charges were assigned to the protein atoms using kollman united atoms force field by using AutoDockTools1.5.6 ${ }^{9}$. The gasteiger partial atomic charges were added and all possible flexible torsion angles of the ligand was defined by using AUTOTORS. The structures were saved in a PDBQT format for AutoDock calculations.

The ligand fisetin structure was drawn using chemsketch. To understand the molecular interaction of fisetin, blind docking of fisetin onto MAO A (2BXR), MAO B (2BYB), COMT (2AVD) and tyrosine hydroxylase (2XSN) proteins was carried out. The docking calculations were carried out using both the Genetic Algorithm and Lamarckian Genetic Algorithm.

\section{Docking Studies and Drug likeness}

Docking calculations were performed to predict the binding affinity between the fisetin and MAO A (2BXR), MAO B (2BYB), COMT (2AVD), tyrosine hydroxylase (2XSN) proteins using AutoDock $4.2{ }^{10}$. AutoDock requires precalculated grid maps, one for each atom type present in the ligand being docked. These maps were calculated by using the auxiliary program AutoGrid. The compounds treated as flexible molecules were allowed to move in the six spatial degrees of freedom for orientation and torsional degrees of freedom within the grid box.

AutoDock uses a semi empirical free energy force field to evaluate conformations during docking simulations. The energy functions define what contributes to the energy of the molecule, like bond stretching, bending etc., so that energy of the molecule can be calculated for any particular conformation. The force field evaluates binding in two steps. In the first step, the intramolecular energetics is estimated for the transition from unbound states to the conformation of the ligand and protein in the bound state. The second step then evaluates the intermolecular energetics of combining the ligand and protein in their bound conformation.

\section{$\Delta \mathrm{G}=\Delta \mathrm{Gvdw}+\Delta \mathrm{Ghbond}+\Delta \mathrm{Gelec}+\Delta \mathrm{G}$ tor $+\Delta \mathrm{Gdesolv}$}

First three terms are for van der Waal's, hydrogen bonding, electrostatics respectively. The term $\Delta$ Gtor is for rotation and translation and $\Delta$ Gdesolv is for desolvation upon binding and the hydrophobic effect 10 . Drug-Likeness and molecular property prediction for the fisetin was done by molsoft.

\section{RESULTS AND DISCUSSION}

The first best five minimum binding energy of fisetin with the 4 drug targets are shown in following table.

Table 1: Minimum Binding Energy of fisetin with the 4 drug targets of the top hits

\begin{tabular}{llclll}
\hline & \multicolumn{2}{c}{ 2BXR: MAO A } & \multicolumn{2}{c}{ 2AVD: COMT } \\
\hline $\mathbf{S} . \mathbf{N o}$ & Run & Minimum Binding Energy & S. No & Run & Minimum Binding Energy \\
$\mathbf{2}$ & 8 & $-10.22 \mathrm{kcal} / \mathrm{mol}$ & 1 & 6 & $-7.45 \mathrm{kcal} / \mathrm{mol}$ \\
$\mathbf{3}$ & 5 & $-10.07 \mathrm{kcal} / \mathrm{mol}$ & 2 & 7 & $-7.36 \mathrm{kcal} / \mathrm{mol}$ \\
$\mathbf{4}$ & 10 & $-9.63 \mathrm{kcal} / \mathrm{mol}$ & 3 & 8 & $-7.26 \mathrm{kcal} / \mathrm{mol}$ \\
$\mathbf{5}$ & 1 & $-9.51 \mathrm{kcal} / \mathrm{mol}$ & 4 & 9 & $-7.22 \mathrm{kcal} / \mathrm{mol}$ \\
& 4 & $-8.98 \mathrm{kcal} / \mathrm{mol}$ & 5 & 5 & $-6.9 \mathrm{kcal} / \mathrm{mol}$ \\
$\mathbf{S} \mathbf{N o}$ & & $\mathbf{2 B Y B : ~ M A O ~ B}$ & & $2 X S N:$ tyrosine hydroxylase \\
$\mathbf{1}$ & Run & Minimum Binding Energy & S. No & Run & Minimum Binding Energy \\
$\mathbf{2}$ & 6 & $-9.68 \mathrm{kcal} / \mathrm{mol}$ & 1 & 7 & $-6.67 \mathrm{kcal} / \mathrm{mol}$ \\
$\mathbf{3}$ & 7 & $-9.42 \mathrm{kcal} / \mathrm{mol}$ & 2 & 6 & $-6.48 \mathrm{kcal} / \mathrm{mol}$ \\
$\mathbf{4}$ & 1 & $-9.02 \mathrm{kcal} / \mathrm{mol}$ & 3 & 9 & $-6.6 \mathrm{kcal} / \mathrm{mol}$ \\
$\mathbf{5}$ & 5 & $-8.69 \mathrm{kcal} / \mathrm{mol}$ & 4 & 4 & $-6.31 \mathrm{kcal} / \mathrm{mol}$ \\
\hline
\end{tabular}


Table 2: Lowest binding energy of fisetin with the 4 drug targets of the top hits

\begin{tabular}{llllll}
\hline S.No. & Protein & $\begin{array}{l}\text { Final Intermolecular Energy (vdW + } \\
\text { Hbond + desolv Energy+Electrostatic } \\
\text { Energy) }\end{array}$ & $\begin{array}{l}\text { Final Total } \\
\text { Internal Energy }\end{array}$ & $\begin{array}{l}\text { Torsional Free } \\
\text { Energy }\end{array}$ & $\begin{array}{l}\text { Unbound } \\
\text { System's } \\
\text { Energy }\end{array}$ \\
\hline $\mathbf{1}$ & MAO A & $-11.71 \mathrm{kcal} / \mathrm{mol}$ & $-1.34 \mathrm{kcal} / \mathrm{mol}$ & $+1.49 \mathrm{kcal} / \mathrm{mol}$ & $-1.34 \mathrm{kcal} / \mathrm{mol}$ \\
$\mathbf{2}$ & MAO B & $-11.18 \mathrm{kcal} / \mathrm{mol}$ & $-1.37 \mathrm{kcal} / \mathrm{mol}$ & $+1.49 \mathrm{kcal} / \mathrm{mol}$ & $-1.37 \mathrm{kcal} / \mathrm{mol}$ \\
$\mathbf{3}$ & COMT & $-8.94 \mathrm{kcal} / \mathrm{mol}$ & $-0.94 \mathrm{kcal} / \mathrm{mol}$ & $+1.49 \mathrm{kcal} / \mathrm{mol}$ & $-0.94 \mathrm{kcal} / \mathrm{mol}$ \\
$\mathbf{4}$ & tyrosine & $-8.17 \mathrm{kcal} / \mathrm{mol}$ & $-1.63 \mathrm{kcal} / \mathrm{mol}$ & $+1.49 \mathrm{kcal} / \mathrm{mol}$ & $-1.63 \mathrm{kcal} / \mathrm{mol}$ \\
& hydroxylase & & & & \\
\hline
\end{tabular}

Figure 2 shows the lowest binding energy conformation of fisetin with MAO, Figure 3 shows the lowest binding energy conformation of fisetin with MAO B. Figure 4 shows the lowest binding energy conformation of fisetin with COMT. Figure 5 shows the lowest binding energy conformation of fisetin with tyrosine hydroxylase. These structures are visualized using chimera ${ }^{11}$. The red color denotes oxygen atom in the ligand fisetin and the blue and orange colored lines denotes the interaction between ligand and the protein molecules.

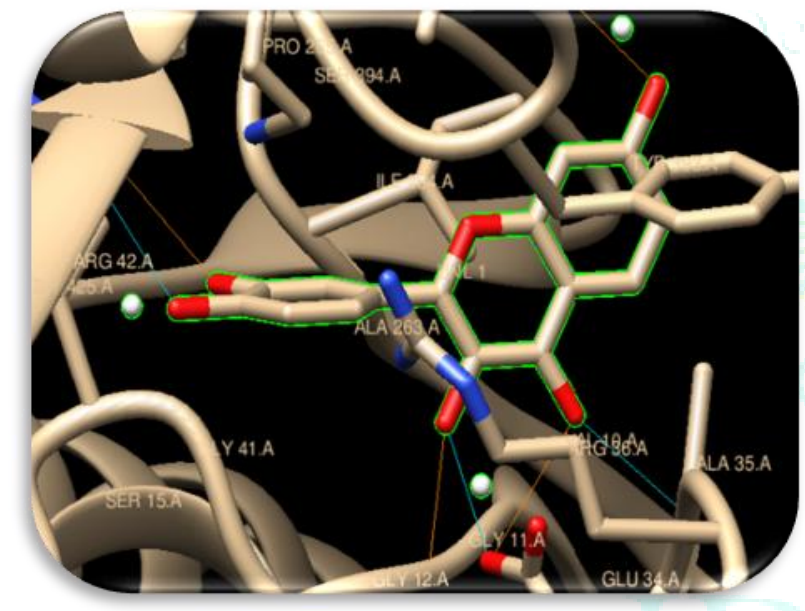

Figure 2: (2BXR-A: MAOA)

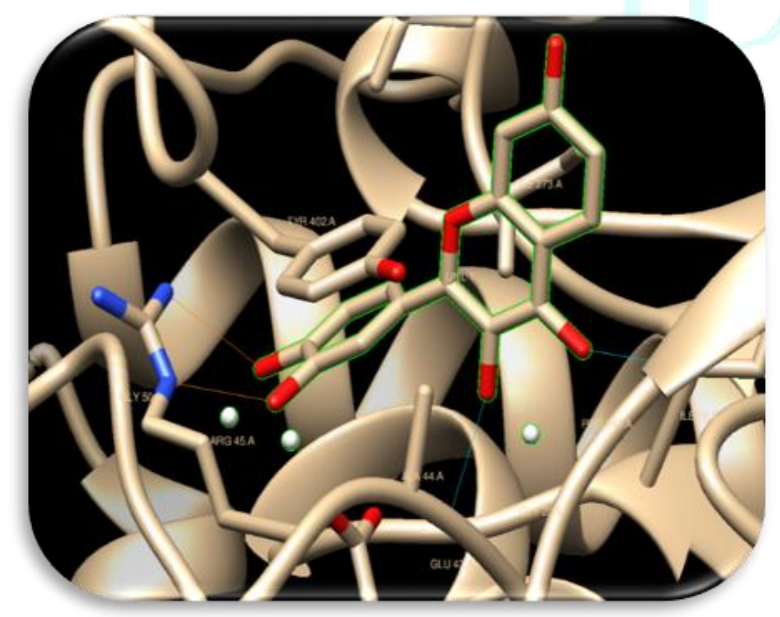

Figure 3: (2BYB-A: MAOB)

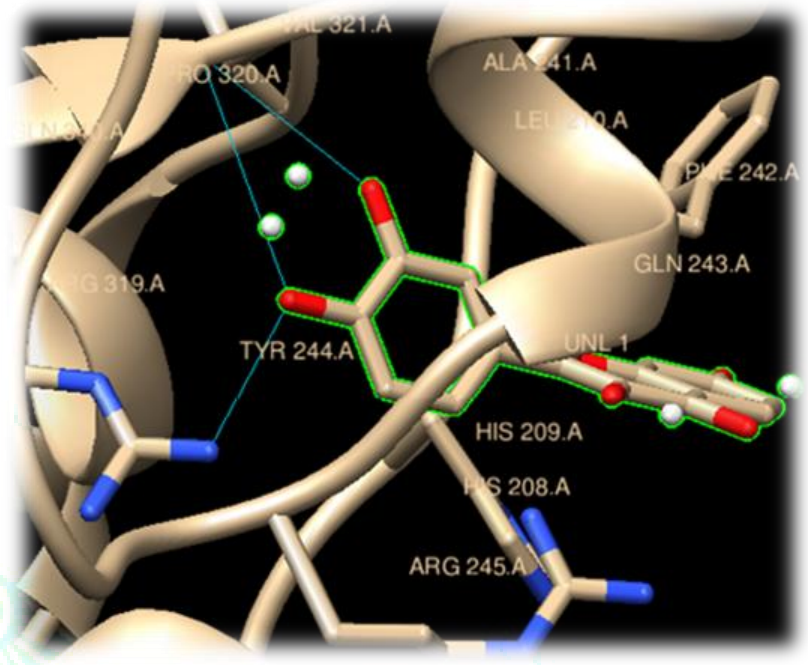

Figure 4: (2AVD-A: COMT)

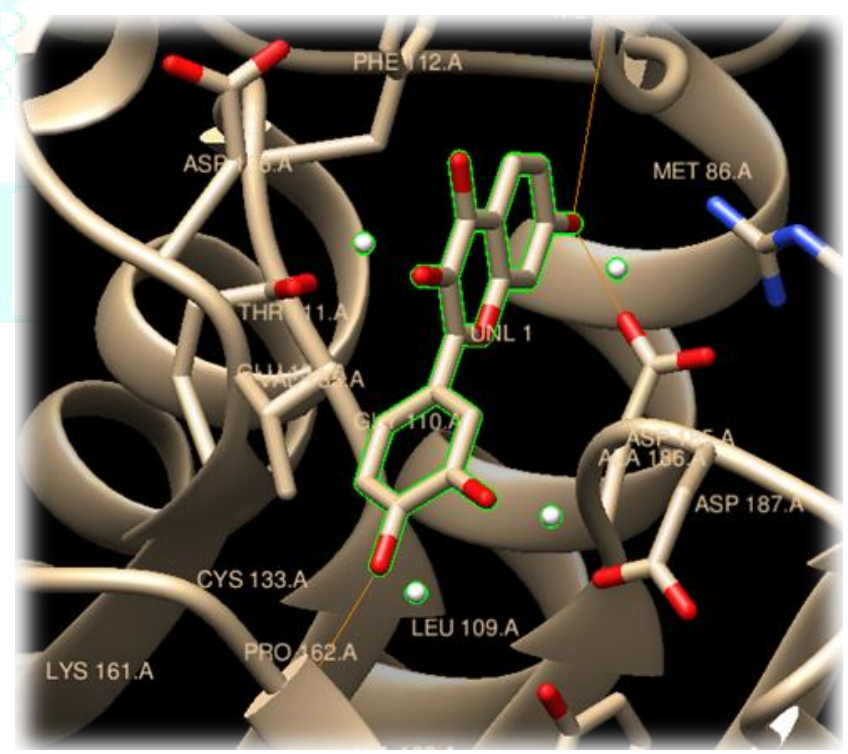

Figure 5: (2XSN-A: tyrosine hydroxylase)

Drug likeness model score of fisetin was 0.76 , shown in figure 6. The molecular properties of fisetin is shown below 


\section{Molecular Properties of fisetin using molsoft}

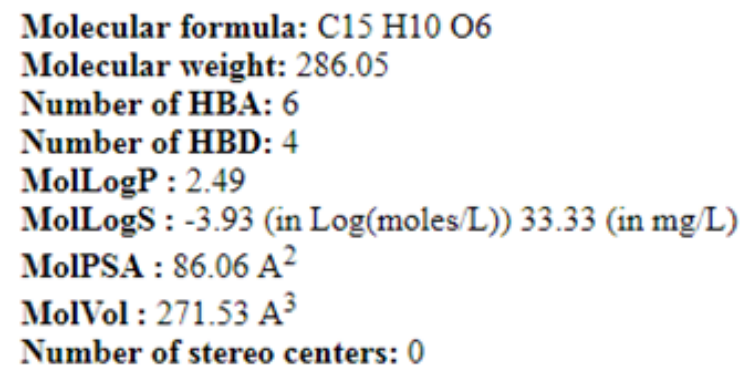

\section{Drug-likeness model score: 0.76}

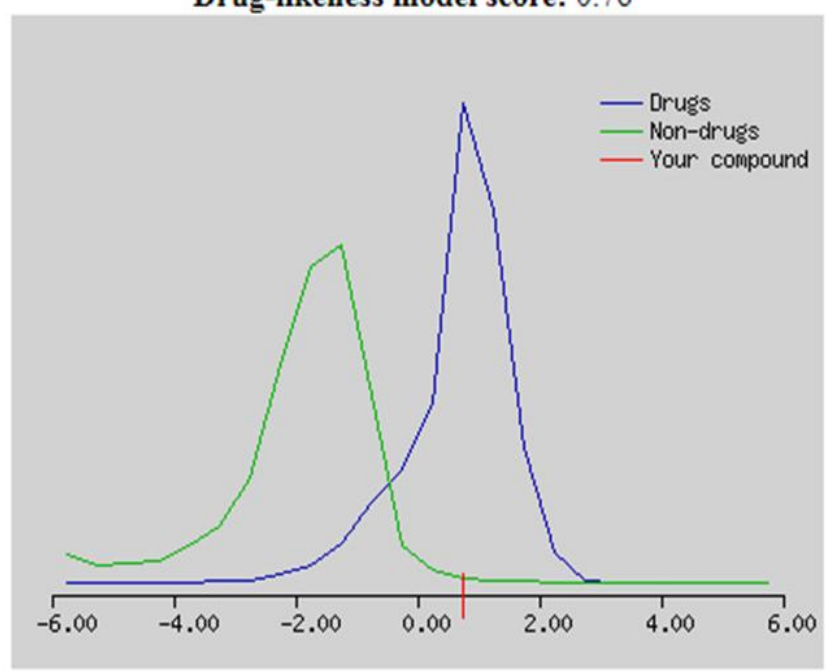

Figure 6: Drug likeness model score of fisetin

\section{CONCLUSION}

In the present study, the binding and interactions of fisetin with MAO A (PDB ID: 2BXR), MAO B (PDB ID: 2BYB), COMT (PDB ID: 2AVD), tyrosine hydroxylase (PDB ID: 2XSN) proteins have been studied using molecular docking calculations. Fisetin has shown significant binding interactions with the MAO A (PDB ID: 2BXR), MAO B (PDB ID:
2BYB), COMT (PDB ID: 2AVD), tyrosine hydroxylase (PDB ID: 2XSN) proteins. Interrupting critical interactions of the biomolecules can solve the "targeted therapy crisis" problem in neurodegenerative diseases. Since, fisetin can interact with the multi-target proteins involved in the development of Parkinson's disease, fisetin can be used to design novel and highly efficient drug for the treatment of Parkinson's disease therapeutics.

\section{REFERENCES}

1. Soto C. Unfolding the role of protein misfolding in neurodegenerative diseases. Nat Rev Neurosci 2003; 4:49-60.

2. Hardy J, Orr H. The genetics of neurodegenerative diseases. J Neurochem 2006; 97:1690-9.

3. Manoharan S, Guillemin GJ, Abiramasundari RS, Essa MM, Akbar M, Akbar MD. The role of reactive oxygen species in the pathogenesis of Alzheimer's disease, Parkinson's disease, and Huntington's disease: a mini review. Oxid Med Cell Longevity 2016. DOI:10.1155/2016/8590578

4. Sonia Angeline M, Sarkar A, Anand K, Ambasta RK, Kumar P. Sesamol and naringenin reverse the effect of rotenone-induced PD rat model. Neuroscience 2013; 254:379-94.

5. Dias V, Junn E, Mouradian MM. The role of oxidative stress in Parkinson's disease. J Parkinson's Disease 2013; 3:461-91.

6. Benavente-García, O.; Castilho, J. Update on Uses and Properties of Citrus Flavonoids: New Findings in Anticancer, Cardiovascular, and Anti-inflammatory Activity. J. Agric. Food Chem., 2008, 56:6185-6205.

7. Naeimia AF, Alizadeh M. Antioxidant properties of the flavonoid fisetin: An updated review of in vivo and in vitro studies. Trends in Food Science \& Technology 2017; 70:34-44.

8. William Dauer and Serge Przedborski. Parkinson's Disease: Mechanisms and models Neuron. 2003; 39:889-909.

9. Morris GM, Goodsell DS, Pique ME, et al. Auto dock4 and AutoDockTools4 automated docking with selective receptor flexibility. J Comput Chem 2009; 16:2785-91.

10. Morris GM, Goodsell DS, Halliday RS, et al. Automated docking using a lamarckian genetic algorithm and an empirical binding free energy function. J Comput Chem 1998; 19:1639-62.

11. Pettersen EF, Goddard TD, Huang CC. et al UCSF Chimera--a visualization system for exploratory research and analysis. J Comput Chem 2004; 25(13):1605-12. 